\title{
Palma forrageira em substituição ao feno de capim-elefante. Efeito sobre consumo, digestibilidade e características de fermentação ruminal em ovinos ${ }^{1}$
}

\section{Safira Valença Bispo ${ }^{2}$, Marcelo de Andrade Ferreira ${ }^{3,4}$, Antonia Sherlânea Chaves Véras ${ }^{3,4}$, Ângela Maria Vieira Batista ${ }^{3,4}$, Ricardo Alexandre Silva Pessoa ${ }^{5}$, Marcela Pimentel Bleuel ${ }^{6}$}

${ }^{1}$ Parte da dissertação da primeira autora apresentada ao PPGZ/UFRPE.

2 PPGZ/UFRPE.

${ }^{3}$ Depto de Zootecnia/UFRPE - Recife - PE.

${ }^{4}$ Bolsista de Produtividade em Pesquisa/CNPq.

5 Programa de Pós-Graduação em Zootecnia/UFV - Viçosa - MG.

${ }^{6}$ Curso de Zootecnia/UFRPE.

RESUMO - Este experimento foi realizado com o objetivo de avaliar o efeito da substituição do feno de capim-elefante por palma forrageira (Opuntia ficus indica, Mill), como fonte de forragem, sobre o consumo e a digestibilidade aparente dos nutrientes e das características ruminais de carneiros. Cinco dietas isoproteícas foram formuladas, em que a palma forrageira substituiu $0,14,28,42$ e $56 \%$ do feno de capim elefante na dieta. Cinco ovinos machos não-castrados foram distribuídos em um delineamento em quadrado latino 5 x 5 (cinco períodos, cinco níveis de palma e cinco repetições). Cada período experimental teve duração de 13 dias - sete para adaptação e seis dias para coleta de dados e amostras. Os consumos de MS, MO, EE, PB, CT, CNF e NDT aumentaram linearmente com a substituição do feno de capim-elefante por palma forrageira na dieta. O consumo de água diminuiu linearmente e o de FDN apresentou efeito quadrático com a substituição do feno de capim-elefante por palma forrageira na dieta. Os coeficientes de digestibilidade aparente de EE, PB, CNF e FDN não foram influenciados, enquanto os de MS, MO e CT aumentaram linearmente com a substituição do feno de capim-elefante por palma forrageira na dieta. $\mathrm{O} \mathrm{pH}$ e a concentração de $\mathrm{NH}_{3}$ ruminal decresceram linearmente com a substituição do feno de capim-elefante por palma forrageira na dieta. A substituição do feno de capim-elefante por palma forrageira na dieta melhora a ingestão e o aproveitamento dos nutrientes.

Palavras-chave: carboidratos, consumo, energia, Opuntia, volumoso

\section{Spineless cactus in replacement of elephantgrass hay. Effect on intake, apparent digestibility and ruminal fermentation characteristics in sheep}

\footnotetext{
ABSTRACT - A study was conducted with the objective to evaluate the effects of replacing elephant-grass by spineless cactus (Opuntia ficus indica, Mill) as a forage source on intake, apparent digestibility of the nutrients and of ruminal fermentation characteristics of sheep. Five iso-nitrogenous diets were formulated where spineless cactus replaced $0,14,28$, 42 and $56 \%$ of elephantgrass in the diet. Five non-castrated male sheep were allotted to a 5 x 5 Latin square design (five periods, five spineless cactus levels and five replications). Each experimental period last 13 day - seven days for adaptation and 6 days for collection of data and samples. Intakes of DM, OM, EE, CP, TC, NFC, and TDN linearly increased as the elephantgrass was replaced by spineless cactus in the diet. Water intake linearly decreased and NDF intake showed a quadratic effect as the elephant grass was replaced by spineless cactus in the diet. The coefficient of apparent digestibilities of EE, CP, NFC and NDF were not affected by spineless cactus, while, apparent digestibilities of DM, OM and TC linearly increased as the elephantgrass was replaced by spineless cactus in the diet. Ruminal $\mathrm{pH}$ and $\mathrm{N}-\mathrm{NH}_{3}$ concentration linearly decreased as the elephantgrass was replaced by spineless cactus in the diet The replacement of elephantgrass by spineless cactus in the diet improve the nutrient intake and nutrient utilization.
}

Key Words: carbohydrates, energy, forage, intake, Opuntia

\section{Introdução}

A região semi-árida anualmente passa por longos períodos de secas, provocando estacionalidade na produção de forragens e forçando os produtores a aumenta- rem os custos de produção, em razão da grande demanda por alimentos concentrados. No entanto, nos últimos anos, é maior o número de pesquisas com enfoque nos alimentos forrageiros alternativos, adaptados à região, para atender às exigências de mantença e produção dos 
animais, a custo viável nos períodos críticos de prolongadas estiagens.

Nessa busca por alimentos que possibilitem a produção animal nos períodos críticos do ano, há várias décadas, a palma forrageira (Opuntia ficus indica Mill) destaca-se por apresentar características morfofisiológicas que a tornam tolerante a longas estiagens (Santos et al., 1997). Este alimento é rico em carboidratos, principalmente nãofibrosos (Wanderley et al., 2002), importante fonte de energia para os ruminantes (Van Soest, 1994), além de apresentar baixa porcentagem de constituintes da parede celular e alto coeficiente de digestibilidade de MS.

Apesar de o teor de fibra ser utilizado como índice negativo de qualidade, uma vez que representa a fração menos digestível dos alimentos, reduzindo o consumo voluntário pelo efeito do enchimento ruminal (Mertens, 1992), a associação da palma aos alimentos fibrosos é fator determinante para um normal funcionamento de atividades como ruminação, movimentação ruminal, homogeneização do conteúdo ruminal e secreção salivar.

Wanderley et al. (2002) e Andrade et al. (2002) avaliaram o efeito da inclusão de palma forrageira ( 0,12 , 24 e 36\%), em substituição à silagem de sorgo para vacas em lactação, sobre a digestibilidade aparente dos nutrientes e o desempenho animal. A proporção de concentrado foi de, aproximadamente, $44 \%$. Não se observou efeito dos tratamentos sobre o consumo de MS e a produção de leite, porém, o teor de gordura do leite e a digestibilidade foram influenciados de forma quadrática - comportamento atribuído ao aumento dos teores de CNF e à redução de FDN, com a crescente inclusão da palma.

Por outro lado, Oliveira (2006) não observou influência da inclusão de palma em substituição ao feno de capimtifton, na dieta de vacas em lactação, sobre o consumo, a produção e composição do leite e digestibilidade da maioria dos nutrientes. Vale ressaltar que, nesse caso, a proporção de concentrado nas dietas foi em torno de $30 \%$ e o teor de CNF e FDN estiveram dentro do intervalo recomendado pelo NRC (2001)

Diante das dificuldades - incertezas climáticas e de produção de forragem no semi-árido -, dietas com maior participação de palma forrageira, cultura plenamente adaptada a estas condições desfavoráveis, deveriam ser utilizadas no intuito de conferir aos sistemas de produção maior sustentabilidade.

Este trabalho foi realizado para avaliar os efeitos da substituição parcial do feno de capim-elefante pela palma forrageira sobre o consumo e a digestibilidade dos nutrientes e parâmetros ruminais em ovinos.

\section{Material e Métodos}

O experimento foi conduzido no galpão de digestibilidade do setor de Caprino-Ovinocultura do Departamento de Zootecnia da Universidade Federal Rural de Pernambuco, no período de novembro de 2005 a janeiro de 2006, em Recife - PE. Foram utilizados cinco ovinos sem padrão racial definido, machos, não-castrados, fistulados no rúmen, em crescimento, com peso vivo médio de $25,8 \pm 3 \mathrm{~kg}$, mantidos em gaiolas individuais dotadas de comedouro, bebedouro e cocho para fornecimento de sal.

Os animais foram distribuídos aleatoriamente em quadrado latino 5 x 5 (cinco períodos, cinco níveis de palma e cinco repetições). Cada período teve duração de 13 dias ( seis para coleta de dados e amostras e sete para adaptação), em concordância com metodologia adotada por Mendonça et al. (2004), Assis et al. (2004) e Souza et al. (2006).

Os tratamentos experimentais consistiram de volumoso e concentrado com cinco níveis de inclusão palma (Opuntia fícus indica Mill) em substituição ao feno de capim elefante: 0, 14, 28, 42 e 56\% (Tabelas 1 e 2).

A ração completa foi fornecida duas vezes ao dia (8 às 14h) e ajustada diariamente, de acordo com o consumo do dia anterior, de modo que as sobras representassem em torno de $10 \%$ do total ofertado, a fim de proporcionar ingestão voluntária e não alterar a proporção dos ingredientes. O consumo de água foi medido diariamente durante o período de coleta, antes e 24 horas após o fornecimento.

Durante o período de coleta, amostras dos alimentos fornecidos e das sobras foram recolhidas diariamente pela manhã, pré-secas em estufa de ventilação forçada e armazenadas para análises. Ao final do experimento, foi feita amostra composta por animal, por período. Posteriormente, todas as amostras foram passadas em peneiras de malha de $2 \mathrm{~mm}$ de diâmetro e analisadas quanto à composição bromatológicas no Laboratório de Nutrição Animal.

Durante quatro dias, a cada 26 horas, foram coletadas amostras da digesta ruminal, correspondentes à hora 0 (antes do fornecimento da ração) e 2, 4 e 6 horas após a alimentação. As amostras foram recolhidas diretamente via fístula ruminal após prévia homogeneização, formando uma amostra composta de $400 \mathrm{~mL}$, para determinação do $\mathrm{pH}$, que foi medido imediatamente após a coleta, com potenciômetro digital.

Para determinação dos teores de MS, matéria mineral (MM), PB e EE, foram utilizadas as metodologias descritas por Silva \& Queiroz (2002). Os teores de FDN e FDA foram 
Tabela 1 - Composição química dos ingredientes das dietas experimentais (\%MS)

Table 1 - Chemicalingredientcomposition of the experimental diets (\% DM)

\begin{tabular}{|c|c|c|c|c|}
\hline \multirow[t]{2}{*}{$\begin{array}{l}\text { Nutriente } \\
\text { Nutrient }\end{array}$} & \multicolumn{4}{|c|}{$\begin{array}{c}\text { Alimento } \\
\text { Feed }\end{array}$} \\
\hline & $\begin{array}{l}\text { Palma } \\
\text { forrageira } \\
\text { Spineless } \\
\text { cactus }\end{array}$ & $\begin{array}{c}\text { Feno de } \\
\text { capim-elefante } \\
\text { Elephantgrass } \\
\text { hay }\end{array}$ & $\begin{array}{l}\text { Farelo de } \\
\text { soja } \\
\text { Soybean } \\
\text { meal }\end{array}$ & $\begin{array}{c}\text { Fubá de } \\
\text { milho } \\
\text { Corn } \\
\text { meal }\end{array}$ \\
\hline $\operatorname{MS}(\%)(D M, \%$ & 9,39 & 87,75 & 89,00 & 88,95 \\
\hline $\mathrm{MO}^{1}(O M)$ & 88,25 & 92,97 & 93,14 & 98,82 \\
\hline $\mathrm{PB}^{1}(C P)$ & 4,90 & 5,85 & 49,59 & 10,82 \\
\hline $\mathrm{EE}^{1}$ & 2,48 & 2,14 & 1,74 & 4,94 \\
\hline $\mathrm{FDN}^{1}(N D F)$ & 32,80 & 80,67 & 16,60 & 16,08 \\
\hline $\mathrm{FDA}^{1}(A D F)$ & 24,18 & 54,81 & 12,29 & 6,10 \\
\hline $\mathrm{CT}^{1}(T C)$ & 80,87 & 84,98 & 41,81 & 83,06 \\
\hline $\mathrm{CNF}^{1}(N F C)$ & 48,07 & 4,31 & 25,21 & 66,98 \\
\hline
\end{tabular}

$1 \%$ na MS (\% of $D M)$.

Tabela 2 - Composições percentual e nutricional das dietas experimentais

Table 2 - Ingredient and chemical compositions of the experimental diets

\begin{tabular}{|c|c|c|c|c|c|}
\hline \multirow[t]{2}{*}{$\begin{array}{l}\text { Ingrediente } \\
\text { Ingredient }\end{array}$} & \multicolumn{5}{|c|}{$\begin{array}{l}\text { Nível de palma forrageira (\%) } \\
\text { Spineless cactus level (\%) }\end{array}$} \\
\hline & 0 & 14 & 28 & 42 & 56 \\
\hline $\begin{array}{l}\text { Feno de capim-elefante } \\
\text { Elephantgrass hay }\end{array}$ & 65 & 51 & 37 & 23 & 9 \\
\hline $\begin{array}{l}\text { Palma forrageira } \\
\text { Spineless cactus }\end{array}$ & 0 & 14 & 28 & 42 & 56 \\
\hline $\begin{array}{l}\text { Fubá de milho } \\
\text { Corn meal }\end{array}$ & 20 & 19,32 & 18,64 & 17,96 & 17,28 \\
\hline $\begin{array}{l}\text { Farelo de soja } \\
\text { Soybean meal }\end{array}$ & 15 & 15,68 & 16,36 & 17,04 & 17,72 \\
\hline
\end{tabular}

Composição química

Chemical composition

\begin{tabular}{lrrrrr}
\hline MS (\%) (DM, \%) & 88,18 & 40,13 & 26,07 & 19,32 & 15,34 \\
$\mathrm{MO}^{1}(O M)$ & 94,17 & 93,44 & 92,77 & 92,07 & 91,37 \\
$\mathrm{~PB}^{1}(C P)$ & 13,40 & 13,54 & 13,68 & 13,78 & 13,92 \\
$\mathrm{EE}^{1}$ & 2,64 & 2,66 & 2,69 & 2,72 & 2,74 \\
$\mathrm{FDN}^{1}(N D F)$ & 58,14 & 51,34 & 44,54 & 37,74 & 30,94 \\
$\mathrm{FDA}^{1}(A D F)$ & 38,69 & 34,44 & 30,20 & 25,95 & 21,70 \\
$\mathrm{CT}^{1}(T C)$ & 78,12 & 77,26 & 76,39 & 75,57 & 74,70 \\
$\mathrm{CNF}^{1}(N F C)$ & 19,98 & 25,81 & 31,65 & 37,52 & 43,36 \\
$\mathrm{NDT}^{1}(T D N)$ & 61,84 & 64,42 & 67,03 & 67,40 & 67,45 \\
\hline
\end{tabular}

$1 \%$ na MS (\% of DM).

analisados segundo metodologia descrita por Van Soest et al. (1991). Para análise dos teores de FDN, as amostras de concentrado e palma forrageira foram mergulhadas em solução de alfa-amilase e uréia a $8 \mathrm{M}$. Para estimativa dos CT, foi utilizada a equação proposta por Sniffen et al. (1992), $\mathrm{CT}=100-(\% \mathrm{~PB}+\% \mathrm{EE}+\% \mathrm{MM})$, e dos $\mathrm{CNF}$, a equação descrita por Mertens (1997), em que $\mathrm{CNF}=100 \%-(\% \mathrm{~PB}+$ $\% \mathrm{FDN}+\% \mathrm{EE}+\%$ cinzas $)$.

A coleta de amostras de fezes foi realizada diretamente na ampola retal dos animais, diariamente $(0,2,4,6,8$ e 10 horas após a alimentação), durante o período de coleta. As fezes foram pré-secas em estufa de ventilação forçada a $60^{\circ} \mathrm{C}$ e, posteriormente, processadas em moinho de peneira com crivo de $2 \mathrm{~mm}$ para futuras análises.

A estimativa da produção de MS fecal foi feita utilizando-se a fibra em detergente ácido indigestível (FDAi) como indicador interno (Cochran et al. 1986). Coletaram-se 1,0 g de cada amostra de fubá de milho, farelo de soja e palma forrageira fornecidos e $0,5 \mathrm{~g}$ de feno de capim-elefante, sobras e fezes. As amostras foram individualmente acondicionadas em sacos de ANKON e incubadas no rúmen de um bubalino com fístula permanente por 144 horas (Craig et al., 1994). Após esse período, as amostras foram retiradas do rúmen, lavadas e analisadas quanto aos teores de FDA, para determinação da fração da fibra remanescente, considerada FDAi. A produção de MS fecal foi estimada pela divisão do consumo do indicador por sua concentração nas fezes. O coeficiente de digestibilidade aparente (CD) foi calculado segundo Silva \& Leão (1979): CD = ((nutriente ingerido- nutriente excretado)/nutriente ingerido)) x 100 .

A análise estatística foi realizada por meio das análises de variância e regressão, de acordo com os níveis de palma forrageira, e os dados foram analisados utilizando-se o pacote estatístico SAEG(UFV, 1998). Os critérios utilizados na escolha do modelo foram a significância dos coeficientes de regressão a $5 \%$ de probabilidade e o coeficiente de determinação $\left(r^{2}\right)$, obtido pela relação entre a soma de quadrados da regressão e a soma de quadrados dos tratamentos e do fenômeno biológico.

\section{Resultados e Discussão}

Quando as proporções de palma forrageira nas dietas aumentaram, o consumo de MS (CMS), nas três formas em que foi expresso, aumentou linearmente, provavelmente em decorrência do efeito crescente na digestibilidade da MS e MO (Tabela 3). Segundo Silva et al. (1997), esta é uma característica importante da palma, diferentemente de outras forragens, pois apresenta alta taxa de digestão ruminal, sendo a MS degradada extensa e rapidamente, favorecendo maior taxa de passagem e, conseqüentemente, consumo semelhante ao dos concentrados.

O aumento linear no CMS pode também ser atribuído à palatabilidade, o que está associado ao elevado nível de carboidratos solúveis (Santos et al., 2001). Esta característica norteia a otimização do consumo alimentar, pois, segundo Ferreira (2005), em razão baixo teor de MS da palma e de sua alta palatabilidade, altas quantidades podem ser consumidas, dependendo da categoria animal, forma de fornecimento da dieta, composição da dieta e do número de refeições. 
Tabela 3 - Valores médios dos consumos de nutrientes, em função dos níveis de palma forrageira Table 3 - Mean values of nutrient intake in function of the spineless cactus levels

\begin{tabular}{|c|c|c|c|c|c|c|c|c|}
\hline \multirow[t]{2}{*}{$\begin{array}{l}\text { Consumo } \\
\text { Intake }\end{array}$} & \multicolumn{5}{|c|}{$\begin{array}{l}\text { Nível de palma forrageira (\% na MS) } \\
\text { Level of spineless cactus (\% DM) }\end{array}$} & \multirow[t]{2}{*}{$\mathrm{CV}(\%)$} & \multicolumn{2}{|c|}{$\mathrm{P}$} \\
\hline & 0 & 14 & 28 & 42 & 56 & & $\mathrm{~L}$ & Q \\
\hline $\mathrm{MS}(\% \mathrm{PV})(D M, \% B W)$ & 2,28 & 2,97 & 3,86 & 4,11 & 3,89 & 20,68 & 0,000 & NS \\
\hline MS $\left(\mathrm{g} / \mathrm{kg}^{0,75}\right)\left(D M, g / \mathrm{kg}^{0,75}\right)$ & 52,29 & 61,87 & 88,88 & 93,84 & 90,47 & 21,92 & 0,000 & NS \\
\hline $\mathrm{MO}(\mathrm{g} / \mathrm{d})(O M)$ & 572,94 & 723,82 & 978,25 & 1008,29 & 1011,22 & 24,71 & 0,002 & NS \\
\hline $\mathrm{PB}(\mathrm{g} / \mathrm{d})(C P)$ & 95,54 & 118,90 & 156,19 & 157,32 & 158,34 & 23,10 & 0,003 & NS \\
\hline $\mathrm{CT}(\mathrm{g} / \mathrm{d})(T C)$ & 491,82 & 617,98 & 834,46 & 860,25 & 858,54 & 24,96 & 0,002 & NS \\
\hline $\mathrm{CNF}(\mathrm{g} / \mathrm{d})(N F C)$ & 144,17 & 234,71 & 369,93 & 438,12 & 513,68 & 22,81 & 0,000 & NS \\
\hline $\operatorname{NDT}(\mathrm{g} / \mathrm{d})(T D N)$ & 393,76 & 512,35 & 743,92 & 748,52 & 771,16 & 20,99 & 0,000 & NS \\
\hline Agua (L/dia) (Water, L/day) & 3,25 & 2,14 & 0,96 & 0,79 & 0,44 & 38,91 & 0,000 & NS \\
\hline $\mathrm{MS}(\% \mathrm{PV})(D M, \% B W)$ & \multicolumn{5}{|c|}{$\hat{y}=2,5502+0,0312 P F$} & 0,80 & & \\
\hline MS $(\mathrm{g} / \mathrm{kg} 0,75)\left(D M, \mathrm{~g} / \mathrm{kg}^{0,75}\right)$ & \multicolumn{5}{|c|}{$\hat{\mathrm{y}}=55,807+0,7737 \mathrm{PF}$} & 0,81 & & \\
\hline $\mathrm{MO}(\mathrm{g} / \mathrm{d})(O M)$ & \multicolumn{5}{|c|}{$\hat{y}=37,715+1,1711 \mathrm{PF}$} & 0,84 & & \\
\hline $\mathrm{FDN}(\mathrm{g} / \mathrm{d})(N D F)$ & \multicolumn{5}{|c|}{$\hat{\mathrm{y}}=331,81+8,7318 \mathrm{PF}-0,1568 \mathrm{PF}$} & 0,85 & & \\
\hline FDN $(\% \mathrm{PV})(N D F, \% B W)$ & \multicolumn{5}{|c|}{$\hat{y}=1,1842+0,0322 \mathrm{PF}-0,0006 \mathrm{PF}$} & 0,86 & & \\
\hline $\mathrm{PB}(\mathrm{g} / \mathrm{d})(C P)$ & \multicolumn{5}{|c|}{$\hat{y}=104,45+1,1716 \mathrm{PF}$} & 0,82 & & \\
\hline $\mathrm{CT}(\mathrm{g} / \mathrm{d})(T C)$ & \multicolumn{5}{|c|}{$\hat{\mathrm{y}}=537,47+6,9695 \mathrm{PF}$} & 0,84 & & \\
\hline $\mathrm{CNF}(\mathrm{g} / \mathrm{d})(N F C)$ & \multicolumn{5}{|c|}{$\hat{y}=151,63+6,7317 P F$} & 0,99 & & \\
\hline NDT (g/d) (TDN) & \multicolumn{5}{|c|}{$\hat{y}=435,75+7,0783 \mathrm{PF}$} & 0,84 & & \\
\hline
\end{tabular}

$\mathrm{P}=$ probabilidade $(P=$ probability $) ; \mathrm{NS}=$ não-significativo $(N S=$ not significant $)$. $\mathrm{PF}=$ nível de palma forrageira $(P F=$ level of spineless cactus).

$L=$ linear; $Q=$ quadrático $(L=$ linear; $Q=$ quadratic $)$.

Resultados semelhantes foram obtidos por Gebremariam et al. (2006), que, ao substituírem palhada por palma na alimentação de ovinos, observaram comportamento quadrático para o CMS com a inclusão de palma, justificado pelo alto conteúdo de água proveniente da palma, que limitaria a ingestão de MS, e pelo alto teor de pectina presente na palma, que, pela rápida fermentação, aumenta a produção de gás ruminal. Esse autores concluíram que a palma pode substituir a palha em até $50 \%$ na MS, com ganho positivo de peso e nenhum distúrbio digestivo nos animais, desde que suplementada com fonte de nitrogênio. No entanto, Nefzaoui \& Ben Salem (1996) concluíram que o nível da cactácea em uma dieta pode alcançar 55\% na MS, sem distúrbio digestivo.

Para o consumo de FDN, em g/dia e \%PV, foi observado comportamento quadrático com a inclusão de palma, estimando-se os consumos máximos em 453,421 g/dia e 1,61\%, respectivamente, com 25,92 e 24,83\% de palma forrageira na dieta. Provavelmente, o incremento no consumo de fibra até esses níveis decorreu do aumento linear no CMS, compensando a oferta decrescente de fibra. Após esses pontos de máxima, o aumento no CMS não compensou a queda na proporção de FDN nas dietas com a inclusão de palma, fato que pode ser atribuído à maior degradabilidade da fibra da palma forrageira em relação à do feno de capim elefante (Carvalho et al., 2002). Outro ponto importante é que, com a adição de palma forrageira, aumentou o aporte de CNF, componente de rápida degradação no rúmen, que pode ter favorecido a atividade microbiana e, conseqüentemente, a digestão.

Os consumos de MO, PB, EE, CHOT, CNF e NDT elevaram-se linearmente com a inclusão de palma, comportamento explicado pelo aumento do consumo de MS e pelos crescentes teores de CNF e NDT (Tabela 2).

O consumo de água diminuiu linearmente à medida que se elevaram os níveis de palma na dieta, em decorrência de maior consumo de água via palma. Este comportamento foi semelhante ao observado por Carvalho et al. (2005) e 
Oliveira (2006), trabalhando com níveis crescentes de palma em dietas para vacas em lactação. Desse modo, ressalta-se a importância da palma como fonte de água para os animais, característica de alto valor para regiões semi-áridas do Nordeste, que sofrem constantemente com as irregularidades das chuvas.

Os coeficientes de digestibilidade de MS, MO e CT aumentaram linearmente com a inclusão de palma em substituição ao feno de capim-elefante (Tabela 4).

Existem inúmeros fatores que influenciam a digestibilidade - consumo de alimentos, proporção e degradabilidade da parede celular, composição do alimento e da dieta, preparo dos alimentos, relação proteína:energia, taxa de degradabilidade e fatores inerentes ao animal (MacDonald et al., 1993; Van Soest, 1994; Ørskov, 2000).

Aumento no consumo de MS pode acarretar menor taxa de digestão, porém, neste estudo, apesar de o CMS ter aumentado, verificou-se incremento na digestibilidade deste nutriente, pois, segundo Ben Salen et al. (1996), a principal diferença entre a palma e outras forrageiras é a maior degradabilidade ruminal dos nutrientes. Analisando os fatores que interferem na digestibilidade, infere-se que, com a adição de palma forrageira, houve alteração na composição da dieta (Tabela 2), principalmente, quantos às proporções de FDN e CNF. Os teores de CNF na dieta aumentaram, visto que são prontamente degradados no rúmen, desaparecendo rapidamente, aumentando o aporte de energia e favorecendo o crescimento microbiano e, conseqüentemente, a digestão.

Os coeficientes de digestibilidade de EE, PB e CNF não foram influenciados pela inclusão de palma na dieta, resultado que corrobora os observados na literatura consultada.

O coeficiente de digestibilidade da FDN não foi influenciado pela adição de palma às dietas. Comportamento diferente foi verificado por Cavalcanti (2005) e Oliveira (2006), que observaram quedas lineares no coeficiente de digestibilidade da FDN, ao incluírem palma na dieta de vacas em lactação em substituição ao feno de capim-Tifton. Os autores atribuíram esta redução ao fato de a palma forrageira apresentar alto teor de CNF, que são fermentados rapidamente no rúmen, com possível diminuição do $\mathrm{pH}$ ruminal e aumento na taxa de passagem, diminuindo a atividade celulolítica e, conseqüentemente, a digestibilidade da fibra. A palma possui, em média, $28,6 \%$ de fibra solúvel em detergente neutro e $7,2 \%$ de ácido galacturônico, o que reporta à elevada quantidade de $\beta$-glucano e/ou frutanas (Batista et al., 2003).

Neste trabalho, o pH ruminal diminuiu linearmente (Tabela 5), com variação de 6,46 a 6,24, para as dietas com 0 e $56 \%$ de palma forrageira, respectivamente. Segundo Hoover \& Stokes (1991), ocorre queda na eficiência de

Tabela 4 - Valores médios da digestibilidade de nutrientes, em função dos níveis de palma forrageira Table 4 - Mean values of nutrient digestibility in function of the spineless cactus levels

\begin{tabular}{|c|c|c|c|c|c|c|c|c|}
\hline \multirow[t]{2}{*}{ Item } & \multicolumn{5}{|c|}{$\begin{array}{c}\text { Nível de palma forrageira (\% na MS) } \\
\text { Level of spineless cactus }(\% \text { DM) }\end{array}$} & \multirow[t]{2}{*}{$\mathrm{CV}(\%)$} & \multicolumn{2}{|c|}{$\mathrm{P}$} \\
\hline & 0 & 14 & 28 & 42 & 56 & & $\mathrm{~L}$ & Q \\
\hline $\operatorname{MS}(D M)$ & 60,55 & 66,01 & 67,99 & 66,14 & 69,57 & 7,53 & 0,023 & NS \\
\hline MO (OM) & 61,83 & 67,26 & 69,25 & 68,61 & 71,52 & 7,33 & 0,012 & NS \\
\hline $\mathrm{EE}(E E)$ & 64,24 & 65,63 & 64,89 & 57,47 & 58,51 & 14,57 & NS & NS \\
\hline FDN $(N D F)$ & 49,61 & 52,71 & 52,59 & 49,07 & 52,69 & 10,04 & NS & NS \\
\hline $\mathrm{PB}(C P)$ & 71,93 & 73,92 & 71,87 & 68,28 & 70,84 & 9,13 & NS & NS \\
\hline CT (TCH) & 62,26 & 68,03 & 70,46 & 70,49 & 73,03 & 6,90 & 0,003 & NS \\
\hline $\mathrm{CNF}(N C F)$ & 91,98 & 92,07 & 92,16 & 92,27 & 88,14 & 5,43 & NS & NS \\
\hline \multirow[t]{2}{*}{ Item } & \multirow{2}{*}{\multicolumn{5}{|c|}{$\begin{array}{l}\text { Regressão } \\
\text { Regression }\end{array}$}} & \multirow{2}{*}{\multicolumn{3}{|c|}{$\mathrm{R} / \mathrm{r}$}} \\
\hline & & & & & & & & \\
\hline $\operatorname{MS}(D M)$ & \multicolumn{5}{|c|}{$\hat{\mathrm{y}}=62,418+0,1298 \mathrm{PF}$} & 0,71 & & \\
\hline MO (OM) & \multicolumn{5}{|c|}{$\hat{\mathrm{y}}=63,55+0,148 \mathrm{PF}$} & 0,82 & & \\
\hline $\mathrm{EE}(E E)$ & \multicolumn{5}{|c|}{$\hat{y}=62,14914$} & - & & \\
\hline $\mathrm{FDN}(N D F)$ & \multicolumn{5}{|c|}{$\hat{\mathrm{y}}=51,33533$} & - & & \\
\hline $\mathrm{PB}(C P)$ & \multicolumn{5}{|c|}{$\hat{\mathrm{y}}=71,36994$} & - & & \\
\hline $\mathrm{CHT}(T C)$ & \multicolumn{5}{|c|}{$\hat{\mathrm{y}}=64,058+0,1714 \mathrm{PF}$} & 0,86 & & \\
\hline $\mathrm{CNF}(N C F)$ & \multicolumn{5}{|c|}{$\hat{\mathrm{y}}=91,32715$} & - & & \\
\hline
\end{tabular}

$\mathrm{P}=$ probabilidade $(P=$ probability $) ; \mathrm{NS}=$ não-significativo $(N S=$ not significant $)$.

$\mathrm{PF}=$ nível de palma forrageira ( $P F=$ level of spineless cactus).

$\mathrm{L}=$ linear; $\mathrm{Q}=$ quadrático $(L=$ linear; $Q=$ quadratic $)$. 
síntese microbiana, com redução no $\mathrm{pH}$ de 6,5 para 5,5. Van Soest (1994) relatou que, de maneira geral, a degradação da fibra é prejudicada com pH abaixo de 6,2.

Outro fator importante seria a taxa de passagem, que tenderia a aumentar com a inclusão de palma com o incremento dos teores de CNF, diminuindo o tempo de atuação dos microrganismos e, em conseqüência, a digestão da fibra. Neste caso, pode ter havido uma compensação, visto que a fibra da palma é bem mais digestível que a do capim-elefante.

Ben Salem et al. (1996) também não observaram alteração na digestibilidade da FDN, ao incluírem palma forrageira na dieta de ovinos recebendo quantidades fixas de palhada de trigo e concentrado.

Nota-se que, com a inclusão de palma na dieta, o pH observado 4 e 6 horas após alimentação diminuiu linearmente. Segundo Batista et al. (2003), 59,5\% dos carboidratos da palma são de rápida e mediana degradabilidade e somente $4,4 \%$ estão indisponíveis. A palma apresenta ainda $12,9 \%$ de amido, valor relativamente alto para as forragens em geral. Esse alto percentual de carboidratos de rápida digestão, provavelmente, aumentou a atividade microbiana e a concentração de AGV, resultando na queda do pH (Tabela 5). Outro aspecto a ser considerado é que a mucilagem contida na palma leva à produção de timpanismo espumoso e, conseqüentemente, pode reduzir a absorção dos AGV, resultando em abaixamento do pH, porém sem comprometimento na digestão dos nutrientes.

Trabalho semelhante foi realizado por Ben Salem et al. (1996), trabalhando com ofertas crescentes de palma $(0,150$, 300,450 ou $600 \mathrm{~g}$ de MS) na dieta de ovinos alimentados com palhada de trigo e concentrado, em que foi verificada queda no $\mathrm{pH}$ ruminal. Resultado semelhante foi observado neste trabalho, visto que a queda do $\mathrm{pH}$ não foi tão pronunciada $(7,16$ a 6,96$)$.

A concentração média de amônia e 4, 6 e 8 horas após a alimentação (Tabela 6) diminuiu linearmente, sendo maior nos animais que receberam a dieta com maior porcentagem de feno. Considerando que as dietas foram isoprotéicas, é provável que a alta digestibilidade e a elevada taxa de digestão da palma forrageira tenham propiciado melhor equilíbrio energia:proteína nos tratamentos que continham esse ingrediente, resultando em menor concentração ruminal de $\mathrm{NH}_{3}$ nos animais que receberam dietas com maiores níveis de palma. Os resultados médios encontrados neste estudo foram superiores aos sugeridos por Satter \& Slyter (1974), citados por Leng (1990), de 5 a $8 \mathrm{mg} / 100 \mathrm{~mL}$, para o máximo crescimento microbiano.

No entanto, as concentrações de amônia do líquido ruminal, antes da alimentação, 2 e 10 horas após a alimentação, não apresentaram efeito significativo para os diferentes tratamentos, encontrando-se no intervalo relatado por Leng (1990), de 10 e $20 \mathrm{mg} / 100 \mathrm{~mL}$, necessário para

Tabela 5 - Valores médio de pH no líquido ruminal, em função dos níveis de palma forrageira e dos tempos de alimentação Table 5 - Means values of ruminal $\mathrm{pH}$ in function of the spineless cactus level and feeding times

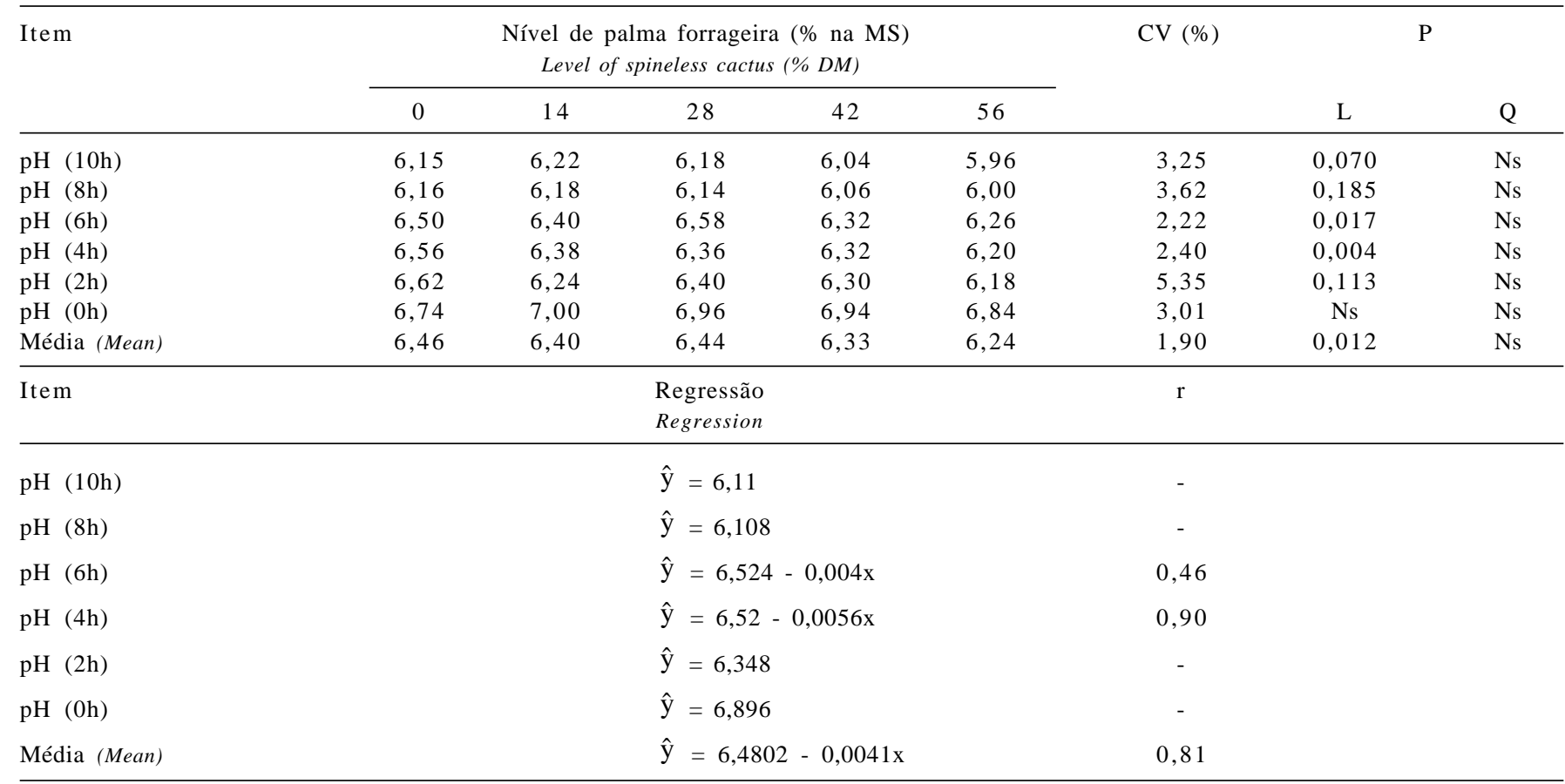

$\mathrm{P}=$ probabilidade $(P=$ probability); NS = não-significativo ( $N S$ = not significant).

$P F=$ nível de palma forrageira $(P F=$ level of spineless cactus $)$.

$L=$ linear; $Q=$ quadrático $(L=$ linear; $Q$ = quadratic $)$. 
Tabela 6 - Valores médios da concentração de amônia $\left(\mathrm{N}-\mathrm{NH}_{3}\right)$ no líquido ruminal $(\mathrm{mg} / 100 \mathrm{~mL})$, em função dos níveis de palma forrageira e dos tempos de alimentação

Table 6 - Mean values of ruminal $\mathrm{NH}_{3}$ concentration $(\mathrm{mg} / 100 \mathrm{~mL})$ in function of the spineless cactus level and time of feeding

\begin{tabular}{|c|c|c|c|c|c|c|c|c|}
\hline \multirow[t]{2}{*}{ Item } & \multicolumn{5}{|c|}{$\begin{array}{l}\text { Nível de palma forrageira (\% na MS) } \\
\text { Level of spineless cactus (\% DM) }\end{array}$} & \multirow[t]{2}{*}{$\mathrm{CV}(\%)$} & \multicolumn{2}{|c|}{$\mathrm{P}$} \\
\hline & 0 & 14 & 28 & 42 & 56 & & $\mathrm{~L}$ & Q \\
\hline $\mathrm{NH}_{3}(10 \mathrm{~h})$ & 16,87 & 13,51 & 15,05 & 15,54 & 14,63 & 37,26 & NS & NS \\
\hline $\mathrm{NH}_{3}(8 \mathrm{~h})$ & 18,34 & 16,10 & 13,16 & 14,35 & 9,94 & 27,45 & 0,00 & NS \\
\hline $\mathrm{NH}_{3}(6 \mathrm{~h})$ & 15,61 & 16,38 & 12,25 & 11,69 & 10,01 & 26,42 & 0,00 & NS \\
\hline $\mathrm{NH}_{3}$ (4h) & 20,44 & 14,35 & 12,46 & 8,75 & 9,17 & 19,81 & 0,00 & 0,00 \\
\hline $\mathrm{NH}_{3}(2 \mathrm{~h})$ & 17,57 & 19,53 & 15,96 & 11,48 & 15,26 & 36,38 & 0,15 & NS \\
\hline $\mathrm{NH}_{3}(\mathrm{Oh})$ & 17,78 & 18,62 & 16,17 & 11,55 & 15,47 & 36,69 & 0,18 & NS \\
\hline Média (Mean) & 17,77 & 16,41 & 14,17 & 12,23 & 12,41 & 14,41 & 0,00 & NS \\
\hline \multirow[t]{2}{*}{ Item } & \multicolumn{5}{|c|}{ Regressão } & $\mathrm{r}$ & & \\
\hline & \multicolumn{5}{|c|}{ Regression } & & & \\
\hline $\mathrm{NH}_{3}(10 \mathrm{~h})$ & \multicolumn{5}{|c|}{$\hat{\mathrm{y}}=15,12$} & - & & \\
\hline $\mathrm{NH}_{3}(8 \mathrm{~h})$ & \multicolumn{5}{|c|}{$\hat{y}=18,088-0,1325 \mathrm{PF}$} & 0,86 & & \\
\hline $\mathrm{NH}_{3}(6 \mathrm{~h})$ & \multicolumn{5}{|c|}{$\hat{y}=16,366-0,1135 \mathrm{PF}$} & 0,86 & & \\
\hline $\mathrm{NH}_{3}(4 \mathrm{~h})$ & \multicolumn{5}{|c|}{$\hat{y}=18,662-0,201 P F$} & 0,88 & & \\
\hline $\mathrm{NH}_{3}(2 \mathrm{~h})$ & \multicolumn{5}{|c|}{$\hat{y}=15,92$} & - & & \\
\hline $\mathrm{NH}_{3}(0 \mathrm{~h})$ & \multicolumn{5}{|c|}{$\hat{y}=14,6$} & - & & \\
\hline Média (Mean) & \multicolumn{5}{|c|}{$\hat{\mathrm{y}}=17,579-0,1064 \mathrm{PF}$} & 0,93 & & \\
\hline
\end{tabular}

promover a máxima digestibilidade e consumo, respectivamente, para forragens de reduzido teor de nitrogênio e baixa digestibilidade.

\section{Conclusões}

O uso de até 56,0\% de palma forrageira em substituição ao feno de capim-elefante aumenta a ingestão e melhora o aproveitamento dos nutrientes em dietas para ovinos.

\section{Literatura Citada}

ANDRADE, D.K.B.; FERREIRA, M.A.; VÉRAS, A.S.C. et al. Digestibilidade e absorção aparentes em vacas da raça holandesa alimentadas com palma forrageira (Opuntia ficus-indica Mill) em substituição à silagem de sorgo (Sorghum bicolor (L.) Moench). Revista Brasileira de Zootecnia, v.31, n.5, p.2088-2097, 2002.

ASSIS, A.J.; CAMPOS, J.M.S.; QUEIROZ, A.C. et al. Polpa cítrica em dietas de vacas em lactação. 2. Digestibilidade dos nutrientes em dois períodos de coleta de fezes, $\mathrm{pH}$ e nitrogênio amoniacal do líquido ruminal. Revista Brasileira de Zootecnia, v.33, n.1, p.251-257, 2004

BATISTA, A.M.V.; DUBEUX JR., J.C.B.; ALMEIDA, O.C. Caracterização química de variedades de palma forrageira. In: REUNIÃO ANUAL DA SOCIEDADE BRASILEIRA DE ZOOTECNIA, 39., 2002, Recife. Anais... Recife: Sociedade Brasileira de Zootecnia, 2002. (CD-ROM).

BATISTA, A.M.; MUSTAFA, A.F.; McALLISTER, T. et al. Effects of variety on chemical composition, in situ nutrient disappearance and in vitro gas production of spineless cacti. Journal of the Science of Food and Agriculture, v. 83, p.440-445, 2003.
BEN SALEN, H.; NEFZAOUI, A.; ABDOULI, H. et al. Effect of increasing level of spineless cactus (Opuntia ficus indica var. inermes) on intake and digestion by sheep given strawbased diets. Animal Science, v.62, n.1, p.293-299, 1996.

CARVALHO, G.G.P.; PIRES, A.J.V.; SANTOS, G.S. et al. Degradabilidade ruminal do capim-elefante, da palma, do guandu e da parte aérea da mandioca. In: REUNIÃO ANUAL DA SOCIEDADE BRASILEIRA DE ZOOTECNIA 39., 2002, Recife. Anais... Recife: Sociedade Brasileira de Zootecnia, 2002. (CD-ROM).

CARVALHO, C.C.; FERREIRA, M.A.; CAVALCANTI. C.V.A. et al. Efeito da substituição do feno de capim Tifton (Cynodon spp) por palma forrageira (Opuntia Fícus indica Mill) sobre o comportamento ingestivo de vacas em Holandesas em lactação. Acta Scientiarum, v.27, n.4, p.505-512, 2005.

CAVALCANTI, C.V.A.; FERREIRA, M.A.; CARVALHO, C.C. et al. Palma forrageira (Opuntia fícus indica mill) e uréia em substituição ao feno de tifton (Cynodon spp) em dietas de vacas holandesas em lactação. Acta Scientiarum, v.28, n.2, p.145$152,2006$.

COCHRAN, R.C.; ADMS, D.C.; WALLACE, J.D. et al. Predicting digestibility of different diets with internal markes: Evaluation of four potential markers. Journal of Animal Science, v.63, p.1476-1483, 1986.

CRAIG, W.M.; HONG, B.J.; BRODERICK, G.A. et al. In vitro inoculum euriched whith particle associated microorganisms for determining rates of fiber digestion and protein degradation. Journal of Dairy Science, v.63, n.5, p.1476-1483, 1986.

FERREIRA, M.A. Palma forrageira na alimentação de bovinos leiteiros. Recife: Universidade Federal Rural de Recife, 2005. p.68.

GEBREMARIAM, T.; MELAKU, S.; YAMI, A. Effect of different levels of cactus (Opuntia ficus-indica) inclusion on feed intake, digestibility and body weight gain in tef (Eragrostis tef) strawbased feeding of sheep. Animal Feed Science and Technology, v.131, p.43-52, 2006.

HALL, M. B. Recentes avanços em carboidratos não-fibrosos na nutrição de vacas leiteiras. In: SIMPÓSIO INTERNACIONAL 
DE BOVINOCULTURA DE LEITE: Novos conceitos em nutrição, 2., 2001, Lavras. Anais... Lavras: Universidade Federal de Lavras, 2001. p.149-159.

HOOVER, W.H.; STOKES, S.R. Balancing carbohydrates and proteins for optimum rumem microbial yield. Journal of Dairy Science, v.74, p.3630-3634, 1991

LENG, R.A. Factors affecting the utilization of "poor-quality" forages by ruminants particularly under tropical conditions. Nutrition Research Reviews, v.3, p.277-303, 1990.

MACDONALD, P.; EDWARDS, R.A.; GREENHALGH, J.F.D. et al. Animal nutrition. 4.ed. Zaragoza: Acribia, 1993. 442p.

MENDONÇA S.S.; CAMPOS, M.S.; VALADARES FILHO, S.C. et al. Consumo, digestibilidade aparente, produção e composição do leite e variáveis ruminais em vacas leiteiras alimentadas com dietas à base de cana-de-açúcar. Revista Brasileira de Zootecnia, v.33, n.2, p.481-492, 2004.

MERTENS, D.R. Análise da fibra e sua utilização na avaliação de alimentos e formulações de rações. In: SIMPÓSIO INTERNACIONAL DE RUMINANTES, 1992, Lavras. Anais... Lavras: Sociedade Brasileira de Zootecnia, 1992. p.188-211.

MERTENS, D.R. Creating a system for meeting the fiber requirements of dairy cows. Journal of Dairy Science, v.80, n.7, p.1463-1481, 1997

NATIONAL RESEARCH COUNCIL - NRC. Nutrient requirements of the dairy cattle. 7.ed. Washigton: D.C.: National Academy Press, 2001. 381p.

OLIVEIRA, V.S. Substituição do milho e parcial do feno de capim Tifton por palma forrageira em dietas para vacas da raça holandesa em lactação. Recife. Universidade Federal Rural de Pernambuco. 2006. 92p. Tese (Doutorado em Zootecnia). Universidade Federal Rural de Pernambuco, 2006.

ØRSKOV, E.R. New concepts of feed evaluation for ruminants with emphasis on roughages and feed intake. Asian-Australasian. Journal of Animal Science, v. 13, p.128-136, 2000.

SANTOS, D.C.; FARIAS, I.; LIRA, M.A. et al. A palma forrageira (Opuntia fícus-indica Mill e Nopalea cochenillifera Salm Dyck) em Pernambuco: cultivo e utilização. Recife: Empresa Pernambucana de Pesquisa Agropecuária, 1997. 23p. (Documentos, 25).

SANTOS, D.C.; SANTOS, M.V.F.; FARIAS, I. et al. Desempenho produtivo de vacas 5/8 Holando/Zebu alimentadas com diferentes cultivares de palma forrageira (Opuntia e Nopalea). Revista Brasileira de Zootecnia, v.30, n.1, p.12-17, 2001.
SATTER, L.D., SLYTER, L.L. Effect of ammonia concentration on rumen microbial production in vitro. Brasilian Journal Nutrition, v. 32, p.199-208, 1974.

SILVA, D.J.; QUEIROZ, A.C. Análise de alimentos: métodos químicos e biológicos. 3.ed. Viçosa, MG: Editora UFV, 2002. $235 \mathrm{p}$.

SILVA, J.F.C.; LEÃO, M.I. Fundamentos da nutrição dos ruminantes. Piracicaba: Livroceres, 1979. 380p.

SILVA, M.F.; BATISTA, A.M.V.; ALMEIDA, O.C. Efeito da adição de capim elefante a dietas à base de palma forrageira sobre a fermentação ruminal em bovinos. In: REUNIÃO ANUAL DA SOCIEDADE BRASILEIRA DE ZOOTECNIA, 34., 1997, Juiz de Fora. Anais... Juiz de Fora: Sociedade Brasileira de Zootecnia, 1997, v.1. p.140-142.

SNIFFEN, C.J.; O'CONNOR, J.D.; van SOEST P.J. et al. A net carbohydrate and protein availability. Journal of Animal Science, v.70, n.11, p.3562-3577, 1992.

SOUZA, A.L.; GARCIA, R.; VALADARES, R.F.D. et al. Casca de café em dietas para vacas em lactação: balanço de compostos nitrogenados e síntese de proteína microbiana. Revista Brasileira de Zootecnia, v.35, n.4, p.1860-1865, 2006.

UNIVERSIDADE FEDERAL DE VIÇOSA - UFV. Sistema de análise estatística e genética - SAEG (manual do usuário). versão 8.0. Viçosa, MG: 1998. 150p.

Van SOEST, P. J. Nutritional ecology of the ruminant. 2.ed. Ithaca: Cornell University Press, 1994. 476p.

Van SOEST, P.J.; ROBERTSON, J.B.; LEWIS, B.A. Methods for extraction fiber, neutral detergent fiber and nonstarch polysaccarides in relation to animal nutrition. Journal of Dairy Science, v.74, n.10, p.3583-3597, 1991

WANDERLEY, W.L.; FERREIRA, M.A.; ANDRADE, D.K.B. et al Palma forrageira (Opuntia ficus indica, Mipp) em substituição à silagem de sorgo (Sorghum bicolor $(\mathrm{L}$.$) ) na alimentação de$ vacas leiteiras. Revista Brasileira de Zootecnia, v.31, n.1, p.273-281, 2002.
Recebido: 6/102006 Aprovado: 31/5/2007 